\title{
Relationship Between IgE-Mediated Sensitization to Staphylococcus aureus Enterotoxin B, Asthma Severity, and Atopy
}

Barranco $\mathrm{P}^{1,2}$, Palao $\mathrm{P}^{1,3}$, Ruiz $\mathrm{I}^{4}$, Domínguez-Ortega $\mathrm{J}^{1,2}$, VilàNadal $\mathrm{G}^{1}$, Pola B ${ }^{1}$, Quirce $\mathrm{S}^{1,2}$

${ }^{I}$ Department of Allergy, La Paz University Hospital, IdiPAZ, Madrid, Spain

${ }^{2}$ CIBER of Respiratory Diseases, CIBERES, Madrid, Spain

${ }^{3}$ Allergy Unit, Regional University Hospital, Malaga, Spain

${ }^{4}$ Department of Intensive Care, Gregorio Marañón University

Hospital, Madrid, Spain

J Investig Allergol Clin Immunol 2021; Vol. 31(2): 170-173

doi: 10.18176/jiaci.0573

Key words: Asthma. Staphylococcus aureus. Enterotoxins. Immunoglobulin E. Atopic dermatitis.

Palabras clave: Asma. Staphylococcus aureus. Enterotoxinas. Inmunoglobulina E. Dermatitis atópica.

The superantigenic properties of Staphylococcus aureus enterotoxins (SEs) (S aureus enterotoxins A [SEA], B [SEB], and $\mathrm{C}[\mathrm{SEC}]$ ) and of toxic shock syndrome toxin (TSST-1) considered as a group have been associated with atopic dermatitis [1], chronic rhinosinusitis [2,3], and asthma [2,4]. The presence of serum specific IgE (sIgE) against a mix of SEs (SE-sIgE) has been suggested as an important risk factor for severe asthma in adult asthma patients with poor lung function and eosinophilia [5-7]. However, few studies analyze each SE individually. In particular, the presence of sIgE to SEB (SEBsIgE) has been associated with severe atopic dermatitis [8], although there is still little evidence of an association between SEB-sIgE and asthma $[9,10]$.

The aim of this study was to determine whether the presence of SEB-sIgE is associated with asthma severity, level of control, and atopy in an asthmatic population.

A retrospective observational study was conducted among patients aged $\geq 18$ years with a diagnosis of asthma in the Severe Asthma Unit at La Paz University Hospital in Madrid, Spain between 2009 and 2013. Sensitization was defined as SEB-sIgE $\geq 0.35 \mathrm{kU} / \mathrm{L}$. The local Clinical Research Ethics Committee approved the study protocol (PI-2986).

Patients were classified based on asthma severity as per the Spanish Guidelines on the Management of Asthma (GEMA) [11]. Uncontrolled patients were those who experienced exacerbations requiring oral corticosteroids for at least 3 consecutive days or admission to hospital in the year prior to the study [12].

Atopy was determined based on the results obtained with skin prick testing and/or sIgE to common aeroallergens, as follows: pollens (Cupressus arizonica, Platanus acerifolia, Olea europaea, Lolium perenne, Artemisia vulgaris, Salsola kali, Parietaria judaica), house dust mites (Dermatophagoides pteronyssinus, Dermatophagoides farinae), animal dander 
(dog, cat), and molds (Aspergillus fumigatus, Alternaria alternata, Cladosporium herbarum, Candida albicans). Skin prick test results were considered positive when a wheal diameter $\geq 3 \mathrm{~mm}$ was obtained in comparison with the negative control (normal saline) in the presence of a positive control (10 $\mathrm{mg} / \mathrm{mL}$ histamine) [13]. An $\mathrm{sIgE}$ value $\geq 0.35 \mathrm{kU} / \mathrm{L}$ was considered positive. The statistical analysis was performed using R.

A total of 266 asthmatic patients were included (75.2\% women) (Table). Average age was 48.42 years (18-83 years); 44 patients $(16.5 \%)$ had positive SEB-sIgE, and $6(13.6 \%)$ were monosensitized to SEB-sIgE.

The average value of SEB-sIgE was $2.15 \mathrm{kU} / \mathrm{L}(0.36-$ $4.50 \mathrm{kU} / \mathrm{L}): 237$ patients $(89.1 \%)$ had uncontrolled asthma, and $101(38 \%)$ had severe asthma; 67 of these required regular treatment with oral corticosteroids $(66.3 \%)$.

Asthmatic patients with positive SEB-sIgE were younger, with a more homogeneous sex distribution, and their asthma was better controlled. In addition, they more frequently had atopic dermatitis, were more frequently sensitized to aeroallergens, and had higher total IgE levels, peripheral blood eosinophil counts, and fractional exhaled nitric oxide (FeNO) values than patients with negative SEB-sIgE. No significant differences were found between the different levels of severity or lung function and the presence of SEB-sIgE. The analyses were repeated to rule out dependence on atopic dermatitis (35 patients with atopic dermatitis were excluded), and significant differences remained with regard to age $(P=.019)$, sex $(P=.004)$, total $\operatorname{IgE}(P=.000)$, and sensitization to house dust mites $(P=.013)$ and fungi $(P=.013)$. The number of eosinophils tended toward significance $(P=.057)$.

We found that $16.5 \%$ of our asthmatic population were sensitized to SEB-IgE; this prevalence is closer to that reported by Tanaka et al [9] $(22.15 \%)$ than to that reported by Matsumoto et al [10] (42\%). These differences may be due to differences in the populations studied and the methodologies used. In our study, about $70 \%$ were moderate-severe asthmatics and $89 \%$ had uncontrolled asthma. In the study by Matsumato et al, less than $20 \%$ were at GINA step 5 and $25 \%$ were poorly controlled. In the study by Tanaka et al, the patients were more

Table. Clinical Characteristics of Asthma Patients

\begin{tabular}{|c|c|c|c|}
\hline & $\begin{array}{l}\text { Patients }(\mathrm{n}=222) \\
\text { SEB-sIgE }(-)\end{array}$ & $\begin{array}{l}\text { Patients }(n=44) \\
\text { SEB-sIgE }(+)\end{array}$ & $p$ \\
\hline Median (range) age, y & $52(18-83)$ & $34.5(18-71)$ & .0002 \\
\hline Female sex, No. (\%) & $176(79.28)$ & $24(54.54)$ & .0009 \\
\hline Smokers, No. (\%) & $25(11.26)$ & $10(22.7)$ & .1 \\
\hline Atopic dermatitis No. (\%) & $23(10.36)$ & $12(27.27)$ & .006 \\
\hline Allergic rhinitis, No. (\%) & $131(59)$ & $30(68.18)$ & .37 \\
\hline CRSwoP, No. (\%) & $74(33.33)$ & $15(34.09)$ & .87 \\
\hline CRSwP, No. (\%) & $61(27.47)$ & $13(29.54)$ & \\
\hline Mild intermittent asthma, No. (\%) & $15(6.75)$ & $2(4.54)$ & .19 \\
\hline Mild persistent asthma, No. (\%) & $39(17.56)$ & $11(25)$ & \\
\hline Moderate persistent asthma, No. (\%) & $78(35.13)$ & $20(45.45)$ & \\
\hline Severe persistent asthma, No. (\%) & $90(40.54)$ & $11(25)$ & \\
\hline Uncontrolled asthma, No. (\%) & $203(91.44)$ & $34(77.27)$ & .035 \\
\hline Median (range) $\mathrm{FEV}_{1} \%$ & $82(29-140)$ & $83.5(30.6-135)$ & .68 \\
\hline Median (range) $\mathrm{FEV}_{1} / \mathrm{FVC} \%$ postBD & $74(32-110)$ & $72(28-86)$ & .26 \\
\hline Median (range) FeNO, ppb & $33(3-267)$ & $56.25(16-180)$ & .03 \\
\hline Median (range) tryptase $\mathrm{ng} / \mathrm{mL}$ & $4.4(0-22.4)$ & $4.55(0-19.6)$ & .48 \\
\hline Median (range) blood eosinophils $/ \mu \mathrm{L}$ & $290(0-192)$ & $375(140-2880)$ & .003 \\
\hline Median (range) ECP, ng/mL & $36(0-180)$ & $52.3(6.20-200)$ & .08 \\
\hline Atopy, No. $(\%)$ & $138(62.16)$ & $34(77.27)$ & .037 \\
\hline Median (range) total IgE, kU/L & $94.5(2.5-2624)$ & $631.5(51-17226)$ & .0000 \\
\hline Sensitization to pollen, No. (\%) & $86(38.74)$ & $25(56.81)$ & .03 \\
\hline Sensitization to mites, No. $(\%)$ & $23(10.36)$ & $13(29.54)$ & .003 \\
\hline Sensitization to animal dander, No. (\%) & $59(26.57)$ & $22(50)$ & .004 \\
\hline Sensitization to molds, No. (\%) & $43(19.36)$ & $19(43.18)$ & .001 \\
\hline
\end{tabular}

Abbreviations: CRSwP, chronic rhinosinusitis with polyposis; $C R S w o P$, chronic rhinosinusitis without polyposis; ECP, eosinophil cationic protein; FEV forced expiratory volume in 1 second; FVC, forced vital capacity; SEB-slgE, specific lgE to staphylococcal enterotoxin B. 
evenly distributed among the severity stages, and $13 \%$ were uncontrolled. Matsumoto et al chose an SEB-sIgE cut-off for positivity of $\geq 0.1 \mathrm{kU} / \mathrm{L}$. Like Tanaka et al, we considered the same cut-off criterion $(\geq 0.35 \mathrm{kU} / \mathrm{L})$ for both $\mathrm{SEB}$ and aeroallergens.

The results in terms of association with asthma control are mixed. Matsumoto et al [10] found that both SEA-sIgE and SEB-sIgE (plus SEA-sIgE) were associated with poorer asthma control. Conversely, Tanaka et al [9], like us, did not find the presence of SEB-sIgE to be associated with poorer asthma control (they only found this association with SEA-sIgE). Again, similar to Tanaka et al, we did not find an association between SEB-sIgE and inflammatory biomarkers (eosinophils in peripheral blood and $\mathrm{FeNO}$ ) or lung function when corrected for atopic dermatitis. Unlike other authors [2,3,5-7], we did not find an association with the presence of chronic rhinosinusitis, probably for the aforementioned reasons and because we did not use a mixture of SEs. It would have been interesting to study the patients who were monosensitized to SEB in our population in order to confirm the results obtained; however, the sample was too small.

The clinical differences found between patients sensitized to SEA and those sensitized to SEB are probably due to the fact that the homology of their amino acid sequences is only $31 \%$ and their mechanisms of binding to $\mathrm{MHC}$ class II molecules are different; SEA is $\mathrm{Zn}^{++}$-dependent and SEB is metal-independent [9]. This means that the immune behaviour of each of the SEs needs to be studied and evaluated individually.

In the asthmatic patients we describe, sensitization to SEB was associated with the presence of atopic dermatitis and with an increased risk of sensitization to common aeroallergens. Sørensen et al [14] found similar results in a cross-sectional study in adolescents (with SEA, SEB, SEC, and TSST), although their cut-off point for SE-sIgE was $>0.1 \mathrm{kU} / \mathrm{L}$. They concluded that sensitization to SEs was associated with polysensitization to food and inhalant allergens, as well as with allergic multimorbidity, thus supporting the mechanism by which $S$ aureus antigens act as T cell-dependent superantigens causing B-cell polysensitization [15]. Another finding that supports this theory is that most authors $[2,5-7,9,10]$, like us, found a stronger association between elevated total IgE levels and SE-sIgE.

Finally, as we are in the age of precision medicine, it is important to underline that sensitization to each enterotoxin should be assessed individually and that the presence of atopic dermatitis should be taken into account, as this could affect the results obtained. Moreover, it is necessary to establish unanimously accepted cut-off points for positive SE-sIgE determinations.

\section{Funding}

The authors declare that no funding was received for the present study.

\section{Conflicts of Interest}

Dr Quirce reports personal fees and nonfinancial support from GSK, AstraZeneca, Sanofi, Novartis, Mundipharma,
Teva, and Allergy Therapeutics outside the submitted work. The remaining authors declare that they have no conflicts of interest.

\section{References}

1. Leung DY, Harbeck R, Buna P, Reiser RF, Yang E, Norris DA, et al. Presence of IgE antibodies to staphylococcal exotoxins on the skin of patients with atopic dermatitis. Evidence for a new group of allergens. J Clin Invest.1993;92:1374-80.

2. Rossi RE, Monasterolo G. Prevalence of serum IgE antibodies to the Staphylococcus aureus enterotoxins (SEA, SEB, SEC, SED, TSST-1) in patients with persistent allergic rhinitis. Int Arch Allergy Immunol. 2004;133:261-6.

3. Pastacaldi C, Lewis P, Howarth P. Staphylococci and staphylococcal superantigens in asthma and rhinitis: a systematic review and meta-analysis. Allergy. 2011;66:54955.

4. Tomassen $P$, Jarvis $D$, Newson $R$, Van Ree $R$, Forsberg $B$, Howarth $P$, et al. Staphylococcus aureus enterotoxin-specific $\lg \mathrm{E}$ is associated with asthma in the general population: a GA2LEN study. Allergy. 2013;68:1289-97.

5. Kowalski ML, Cieslak M, Pérez-Novo CA, Makowska JS, Bachert C. Clinical and immunological determinants of severe/refractory asthma (SRA): association with staphylococcal superantigen-specific IgE antibodies. Allergy. 2011;66:32-8.

6. Bachert C, Van Steen K, Zhang N, Holtappels G, Cattaert T, Maus B, et al. Specific IgE against Staphylococcus aureus enterotoxins: an independent risk factor for asthma. J Allergy Clin Immunol. 2012;130:376-81.

7. Song WJ, Sintobin I, Sohn KH, Kang MG, Park HK, Jo EJ, et al. Staphylococcal enterotoxin IgE sensitization in late-onset severe eosinophilic asthma in the elderly. Clin Exp Allergy. 2016;46:411-21.

8. Breuer K, Wittmann M, Bosche B, Kapp A, Werfel T. Severe atopic dermatitis is associated with sensitization to staphylococcal enterotoxin B (SEB). Allergy. 2000;55:5515.

9. Tanaka A, Suzuki S, Ohta S, Manabe R, Furukawa H, Kuwahara $\mathrm{N}$, et al. Association between specific IgE to Staphylococcus aureus enterotoxins $A$ and $B$ and asthma control. Ann Allergy Asthma Immunol. 2015;115:191-7.

10. Matsumoto H, Kanemitsu Y, Nagasaki T, Tohda Y, Horiguchi T,

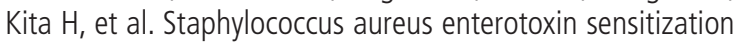
involvement and its association with the CysLTR1 variant in different asthma penotypes. Ann Allergy Asthma Immunol.2017;118:197-203.

11. GEMA 2009 (Spanish guideline on the management of asthma). J Investig Allergol Clin Immunol. 2010;20Suppl 1:159.

12. Chung KF1, Godard P, Adelroth E, Ayres J, Barnes N, Barnes $P$, et al. Difficult/therapy-resistant asthma: the need for an integrated approach to define clinical phenotypes, evaluate risk factors, understand pathophysiology and find novel therapies. ERS Task Force on Difficult/Therapy-Resistant Asthma. European Respiratory Society. Eur Respir J. 1999;13:1198-208. 
13. Bousquet J, Heinzerling L, Bachert C, Papadopoulos NG, Bousquet PJ, Burney PG, et al. Practical guide to skin prick tests in allergy to aeroallergens. Allergy. 2012;67:18-24

14. Sørensen M, Klingenberg ,Wickman M, Sollid JUE, Fusberg AS, Bachert C, et al. Staphylococcus aureus enterotoxin sensitization is associated with allergic poly-sensitization and allergic multimorbidity in adolescents. Allergy. 2017;72:154855.

15. Abdurrahman G, Schemiedeke F, Bachert C, Bröker BM, Holtfreter $S$. Allergy-A new role for T cell superantigens of Staphylococcus aureus? Toxins. 2020;12:176.

Manuscript received April 28, 2020; accepted for publication June 29, 2020.

Pilar Barranco

Department of Allergy

La Paz University Hospital

Madrid, Spain

E-mail: mpbarranco@gmail.com 